\title{
Cosecheros-huerteros: bajo la sombra de los monopolios cacaoteros del Guayaquil colonial*/
}

\author{
Cosecheros-huerteros: Under the Shade of the Cocoa \\ Monopolies of the Colonial Guayaquil
}

\author{
Luisa Consuelo Soler Lizarazo \\ Universidad Autónoma de Chile
}

El propósito de este escrito es reconocer la participación de los cosecheros-huerteros en los procesos internos de las redes que controlaron el comercio agro-exportador y mercantil en el Guayaquil colonial. Sobre fuentes notariales del Archivo Histórico del Guayas se desentrañan negociaciones, contratos y querellas. En síntesis, el artículo deja al descubierto una gama de estrategias e intereses, desavenencias y vicisitudes propias de quienes intervinieron en la cadena productiva y operativa del tráfico del cacao.

Palabras Claves: Cosecheros; Cacaoteros; Comercio; Monopolios; Redes; Negocios.

The purpose of this writing is to admit the participation of the cosecheros-huerteros in the internal processes of the networks that they controlled the agro-exporting and mercantile trade in the colonial Guayaquil. On sources of the Historical Archive of Guayas unravel negotiations, contracts and disputes. In synthesis, the article reveals a range of strategies and interests own; disagreements and vicissitudes of those involved in the productive and operative chain of the traffic of the cocoa.

KEYwORDS: Harvesters; Cacaoteros; Trade; Monopolies; Networks; Business.

* Este artículo es producto de una estancia investigativa en el Archivo Histórico del Guayas, financiada por el Instituto Panamericano de Geografía e Historia (IPGH), seccional México, en el marco del Proyecto His 2.1.3.2.2.1 «Expresiones de la ilustración en el mundo hispánico. Una empresa Novohispana en el tráfico mercantil con Santafé, Quito y Guayaquil en el siglo XVIII», Guayaquil, 2009. Actualmente forma parte del proyecto N. ${ }^{\circ} 11130190$ Fondecyt-Chile. 


\section{Introducción}

La ciudad y la provincia de Guayaquil estuvieron en letargo algo más de trescientos cincuenta años a pesar de contar con importantes recursos para el desarrollo económico; el detonante para su florecimiento según Laviana se inició en el último cuarto del siglo XVIII producto de tres cambios estructurales: libertad de comercio, reducción de impuestos y ampliación de los mercados. ${ }^{1}$ Análogamente ese despertar de Guayaquil también tardó historiográficamente en ser registrado. En efecto a mediados del siglo XX aún no había despertado el suficiente interés investigativo por analizar de manera integral la región del Guayas y su relación con el medio ambiente y la economía. De hecho, el trabajo pionero de Erneholm ${ }^{2}$ sobre desarrollo y distribución geográfica de la producción de cacao en Sudamérica, solo fue retomado años después por León Borja y Szaszdi quienes publicaron un ensayo dedicado al comercio del cacao de Guayaquil. ${ }^{3}$ Es hasta la década del setenta, cuando Hamerly realizó estudios cuantitativos sobre el tráfico de la almendra y sus relaciones con los eslabonamientos internos regionales y con el exterior. ${ }^{4}$ A su vez, algunos temas de historia económica regional se orientaron al estudio del puerto de Guayaquil, los astilleros, los indios balseros y el tráfico comercial interno. ${ }^{5}$

Una década después los análisis sobre haciendas, producción y comercio dieron su fruto. Se destacan los aportes de Laviana sobre la organización y funcionamiento de las Cajas Reales de Guayaquil; ${ }^{6}$ el fenómeno oligárquico en torno al cacao y las relaciones entre propietarios y sembradores estudiado por Chiriboga. ${ }^{7}$ Los años ochenta se cierran con aportes sobre el desarrollo económico integral del Guayas con especial atención en los recursos naturales. ${ }^{8}$ Desde entonces, los estudios se ampliaron a los actores y agentes económicos como las elites cacaoteras y los emporios mercantiles del sector exportador. ${ }^{9}$ De hecho, Dueñas focalizó en la resis-

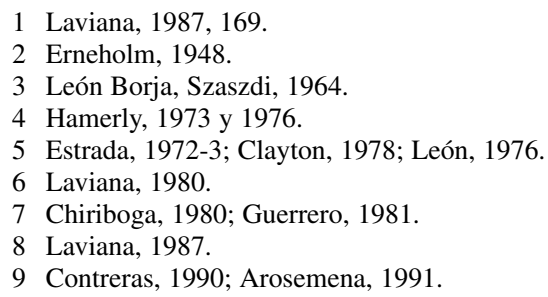


tencia de Portoviejo y la emancipación política de los marqueses, cacaoteros y vecinos de ese partido. ${ }^{10}$

A su vez, en otras latitudes el estudio del tráfico cacaotero también rindió sus frutos. La historiografía mexicana avanzó sobre el estudio del cacao de Guayaquil en Nueva España, examinándose su dinámica comercial al interior del virreinato novohispano y sus conexiones con el comercio exterior. ${ }^{11}$

En los últimos años, el trabajo conjunto de diferentes historiadores interesados en profundizar en la dinámica comercial ha favorecido la reconstrucción de las redes que operaron allende las fronteras del Atlántico y del Pacífico. Dentro de esta perspectiva, se destacan las investigaciones sobre el tráfico de la mencionada almendra en la América hispánica y su efecto integrador entre Guayaquil y Nueva España; análisis que a su vez ha trascendido los espacios interregionales entre las dos Américas, esto es, con el mundo europeo y asiático. ${ }^{12}$

De hecho, este artículo está sustentado sobre los resultados de un trabajo relacionado con las dinámicas mercantiles surgidas a partir del tráfico del cacao. El estudio demostró una alta correspondencia articuladora entre zonas económicas heterogéneas, esto es, entre los partidos productores del fruto en el Guayas y los diferentes mercados consumidores tanto en el exterior como en los regionales intermedios.

El notable desempeño económico de la región a finales del siglo XVIII fue producto del elemento humano, de aquellas complejas redes que intervinieron directa e indirectamente para que los tratantes de la almendra formaran parte del círculo elitista del gremio exportador americano. Los resultados saltaron a la vista cuando los cacaoteros avecindados en Guayaquil negociaban a la par con los grandes comerciantes limeños, gaditanos y novohispanos. ${ }^{13}$ No sorprende entonces que en Guayaquil los exportadores de cacao fueran a la vez inversionistas navieros, prestamistas y financistas. El reconocimiento de la diversificación en los negocios y del éxito agro-exportador es indudable. ${ }^{14}$

10 Dueñas, 1997.

11 Hernández, 2008; Miño, 2009; Del Valle, 2010.

12 Miño, 2009; Soler, 2010.

13 Soler, 2010.

14 Mazzeo, 1999; Soler, 2010; Del Valle, 2010. 
Sin embargo, una revisión a las entramadas relaciones reveló que estos grupos monopólicos necesitaron de un eficaz sistema operativo interno para el desarrollo de su comercio y por ende de sujetos que les aseguraran la provisión del fruto para armar las expediciones hacia el exterior, generalmente pactadas mediante contratos previos. De hecho, fueron los grupos locales de cosecheros plantadores quienes, actuando al interior de los corregimientos, constituyeron la base de la esfera productiva y los eslabones que unieron la cadena de enlaces entre redes productoras, comercializadoras y exportadoras.

Aun así y a pesar de su significativa actuación en todo el engranaje que implicó el tráfico del cacao, a la fecha poco se ha avanzado en su estudio. De hecho, lo aquí expuesto solo se limita a revisar de manera sucinta algunas formas de participación de los cosecheros dentro de los procesos internos de las redes de los grandes cacaoteros de fines del siglo XVIII.

Generalmente, los plantadores cosecheros eran productores individuales heterogéneos que, involucrados directa o indirectamente, participaron en el encadenamiento productivo del grano. Algunos fungieron como pequeños cosecheros-huerteros, oficio que les convirtió en surtidores permanentes y/o regulares de cacao; otros operaron dentro del rango de medianos plantadores actuando habitualmente como intermediarios. Además de sus cosechas para la venta, compraban lotes de cacao a los lugareños para negociarlos con los grandes mayoristas y/o con los exportadores del fruto. En la cima se ubicaron los grandes cacaoteros-hacendados-comerciantes, grupos selectivos y minoritarios generalmente adscritos a las amplias redes de comercio exterior.

Estos lugares yuxtapuestos entre unos y otros nos invitan a revisar algunas formas particulares de participación dentro de los procesos internos de las redes. Considerados como pilares indispensables para sostener la producción y comercialización interna del fruto, los pequeños y medianos productores son el horizonte del texto; sobre casos puntuales extraídos de contratos, demandas y querellas instauradas por los mismos protagonistas en lo que fuera la audiencia de Quito y la provincia del Guayas se da cuenta fehaciente de su participación. De ahí que son los fondos Escribanos Públicos, Judiciales, Pesos, Protocolos y Notarías los que nos permiten ir al interior de las dinámicas en el ejercicio de su oficio y a los procesos internos de las redes que controlaron el comercio agro-exportador y mercantil en el Guayaquil colonial. 


\section{Formas de operación y participación}

\section{Cosecheros-huerteros: pilares de la producción agrícola y económica}

Favorecidos por las condiciones naturales y la fertilidad del suelo los guayaquileños cosecharon principalmente cacao, siendo este es un fruto que se produce en mazorcas compuestas por semillas. Una vez alcanzada la condición de almendra lo comercializaron en forma de grano sin someterlo al requerido proceso de fermentación, secado y molienda. Es probable que por su carácter de uso múltiple (alimento, medicina, moneda, símbolo y cultura) los traficantes de este fruto prefirieran mantenerlo en estado natural.

Debe recordarse que desde épocas prehispánicas se le habían conferido significantes simbólicos y monetarios: «más lo que generalmente de él se usa es para moneda y corre por toda la tierra». ${ }^{15}$ En efecto, posteriormente en el nuevo orden económico el cacao fue equiparado con la moneda española, quizás esto explica en parte por qué los guayaquileños prefirieron las bondades de plantarlo y cosecharlo antes que procesarlo.

De hecho, la dedicación exclusiva a la cosecha y a la exportación en su estado natural influyó en buena medida para desatender prometedores proyectos para su semi-procesamiento, como el propuesto por Francisco Requena en su Descripción de Guayaquil en 1774:

Fuera menos costosa la conducción del cacao de esta provincia, y se conserva mejor sin que se evaporizasen sus partes aromáticas y oleosas que lo constituyen delicado, remitiéndolo molido en grandes pastas dentro de dobles cajones de roble o cedro, que es por acá barato y abundante, cuya madera no sería despreciable en Europa. ${ }^{16}$

Mantener el producto original pensando en su destino final habría sido una de las razones por las cuales esta propuesta visionaria de valor agregado resolvía los problemas de conservación, transporte, almacenamiento y costos, aun así no hizo eco en los mercaderes cosecheros de Guayaquil. Las razones hipotéticas del destino final, en este caso, por su valor monetario se entienden mejor por la certeza de cerrar negocios con cacao de buena calidad y en grano valorado como una especie de moneda. Cuando era destinado para consumo, las garantías de su pureza no eran las mismas que con

15 Benavente, 1984, 153-154.

16 Arosemena, 1991, 545; Laviana, 1984, 58. 
el fruto molido, pues es sabido que constantemente era alterado con harinas para aumentar su peso. Así, por ejemplo, en Nueva España fue reiterativa la queja de «venderlo sucio y el de mezclar el cacao con maíz prieto u otra semilla tostada cuando lo venden reducido a pasta». ${ }^{17}$

Al final siendo Nueva España el principal mercado de la América española al que apostaron los guayaquileños y uno de los frutos de mayor consumo, y aprovechando que los mexicanos desde tiempos prehispánicos encontraron las mejores maneras de matizar su gusto amargo sometiéndolo a un proceso de transformación permanente, los guayaquileños prefirieron su comercialización en grano. ${ }^{18}$

En consecuencia el desafío para aquellos exportadores no era tanto la innovación y el semi-procesamiento de la almendra, el mayor problema del momento era la escasez de circulante, de ahí el uso preferente en su estado natural como bien valor.

Ante estas circunstancias y en un contexto favorable para la explotación de tierras fértiles con suficiente mano de obra, las plantaciones y cosechas serían su especialización. La lógica económica del funcionamiento de parcelas y/o pequeñas huertas cacaoteras fue una estrategia básica de pura subsistencia y de autoconsumo. Cuando los huerteros necesitaban de otras mercaderías pagaban con el fruto producto de su propiedad individual y cuando requerían caudales líquidos daban en garantía sus árboles frutales; de tal forma que los cosecheros-huerteros en el ejercicio de su oficio podían desempeñarse solamente como sembradores y/o distribuidores de los frutos producidos sin ejercer propiamente el comercio.

Existieron tantas modalidades como situaciones particulares para involucrarse con el cultivo del fruto. Incluso es significativo cómo algunos individuos sin tener ocupación declarada como cosecheros se vieron obligados a serlo con tal de poder cumplir con las obligaciones pactadas en otros negocios comerciales. El caso de don Diego Bayas y Lacuadra vecino de la ciudad de Guayaquil representa esa situación:

juro conforme a derecho, parezco ante vuestra alteza y digo: que por mi parte en el año setenta y nueve era deudor a don Manuel Barragán del mismo vecindario

17 Archivo General de la Nación, México (AGNM), Hacienda, 1152, 13, Declaración del procurador del ayuntamiento de la ciudad de México sobre precios, México, 1768.

18 Las técnicas de preparación permanecieron inalterables desde que el cacao se domesticó. Una vez que pasaba por el proceso de cosecha y preparación del grano, éste se molía; la pasta resultante se mezclaba con agua y se le añadían las semillas, las hojas o las flores de otras plantas como vaini1la, achiote o chile. Revista Arqueología Mexicana, 45, 64. 
de la cantidad de dos mil pesos y como el viaje que hizo para Lima hubiese naufragado, y perdido todos los intereses que llevaba propios y ajenos se vio para reparar este infortunio la precisión de entregarse a cultivar una huerta de cacagual y comprar otra. ${ }^{19}$

El acreedor Manuel Barragán, capitán de Granaderos no dudó en recobrar sus caudales acudiendo a la conocida maniobra de obligar a los deudores a cultivar cacao. Dependiendo de las circunstancias particulares regularmente los cosecheros-huerteros cambiaban de modalidad, incluso la posibilidad de producir la almendra y comerciarla era factible. De ahí que, una vez convertidos en minoristas locales, podían comprar a nombre de otros siendo su función principal entregar el cacao a quienes patrocinaban las exportaciones. Estos grupos de intermediarios incluidos dentro de un sistema jerárquico de organización y distribución se encargaban principalmente de organizar lotes de cacao desde sus partidos o distritos hasta la ribera del Guayas. Previamente controlados por los grupos monopólicos, entregaban el fruto a los grandes mayoristas y/o a los exportadores.

No siempre los intermediarios fueron la conexión con los pequeños cosecheros. En ocasiones los mismos exportadores negociaban directamente con los huerteros sobre todo cuando eran pactados los frutos como medio de pago sobre préstamos de caudales y/o como garantías de otros negocios. A su vez, los pequeños plantadores también podían pactar sin intermediarios, todo dependía de la ubicación, del estado de las cosechas, de la demanda del fruto, de la disponibilidad de recursos, de los negocios a tratar y de las deudas a cubrir.

Si bien los moradores participaban abiertamente en la producción, el transporte y distribución interna del fruto, su negociación y comercialización estuvo fuertemente controlada; la manipulación de los precios por parte de quienes monopolizaban el fruto les generó desventajas y hasta pérdidas a la hora de vender sus cosechas. Para quienes tuvieron que pasar por más de un intermediario los beneficios no siempre fueron los mejores; en tanto que aquellos productores, principalmente de Baba y Babahoyo, que transportaban el fruto sin recurrir a los tratantes en algo favorecieron sus ganancias. ${ }^{20}$

19 Archivo Histórico del Guayas, Guayaquil (AHG), Escribanos públicos y judiciales, 5458, Resumen del expediente por autos seguidos por Diego Bayas contra Manuel Barragán, Guayaquil, 1784-1793.

20 Estrada, 1772, 68. 
Todas estas razones llevaron al común de los cosecheros plantadores a delegar el comercio de sus frutos a los grupos monopólicos exportadores a la espera del beneficio, en un comercio nada fácil, pues todo aquel que se dedicara al tráfico exterior de este fruto tendría que arriesgar en la navegación, controlar la masificación ocasionada por la presencia de comerciantes temporeros, competir con desembarcos furtivos, batallar con las reglamentaciones comerciales, entre otros problemas. Ante un negocio de tal envergadura los grandes tratantes de cacao aprovecharon el mecanismo estratégico de operar en red convirtiéndolo en un tráfico altamente monopolizado; controlaron coberturas de mercados, establecieron contactos políticos y comerciales allende sus fronteras, mantuvieron información oportuna sobre el comportamiento del mercado, prácticas de largo alcance que supusieron una organización sistemática en circuitos mayores.

A su vez los exportadores cacaoteros utilizaron la figura de factores en circuitos internacionales, entregando el cacao del vecindario de Guayaquil a negociantes experimentados en las diferentes plazas del exterior. Un documento registrado ante notaría por Jacinto Bejarano confiriendo amplio poder y suficiente para realizar su venta en Nueva España a Nicolás Gómez Cornejo, ${ }^{21}$ representa esta figura:

para que en mi nombre y representando a mi propia persona derechos y acciones pueda bender y benda en dicho reyno siete mil veitinueve cargas de cacao que de mi cuenta, costo y riesgo siguen en la referida mi fragata, como también tres mil novecientos setenta y siete cargas pertenecientes al vecindario de la referida ciudad de Guayaquil, quien por este me ha dado facultad para expender este número. ${ }^{22}$

Efectivamente, dentro del marco del libre comercio las existencias de las bodegas novohispanas se saturaron, mientras que en los registros de aduanas apenas alcanzaban las diez mil fanegas autorizadas. Este comportamiento se conoce por las cuentas y documentos contables del comerciante Francisco de Yraeta en Nueva España y sus corresponsales en Guayaquil, quien llegó a concentrar en sus manos en 1789 un mínimo de 16.551 cargas de cacao Guayaquil. ${ }^{23}$

21 Nicolás Cornejo tenía amplia experiencia en el manejo del comercio con otras zonas americanas. En 1773 había operado en Realejo y Sonsonate, comercializando principalmente añil.

22 Archivo Histórico de Notarías, México (AHNM), Notarías, 155, Carta poder del señor coronel don Jacinto Bejarano a su apoderado Nicolás Gómez Cornejo, México, 1790.

23 Soler, 2010, 478. 
Es evidente que comportamientos como estos de aumento en la producción de fruto para la exportación implicaron necesariamente una significativa participación de los cosecheros-huerteros.

\section{Cultivo para todos: optimismo y confianza en un negocio prometedor}

El pequeño o mediano cosechero necesitó escasa mano de obra para las plantaciones cacaoteras. En efecto, un plantador podía hacerse cargo del cuidado de mil plantas, que en condiciones normales rendían dos mil libras de cacao al año, es decir, 25 cargas. Con diez mil plantas necesitaba solamente diez trabajadores permanentes. En la producción de esos diez mil árboles, se calculan en promedio unas 250 cargas de cacao anuales, que en el mercado local, a cuatro pesos carga, significaban mil pesos. Para esta plantación, los costos de producción no superaban los 300 pesos, promediándose entre 8 a 10 reales el costo por carga. En condiciones de buenas cosechas se obtenía un beneficio anual de 700 pesos, valor equivalente a los ingresos de un funcionario estatal de mediana jerarquía. En tanto que a quienes actuaban bajo el sistema de contrata (generalmente nativos) se les encargaba el cultivo y el cuidado redimiéndoles entre 6 y 7 reales por planta entregada. ${ }^{24}$

Las plantaciones cacaoteras si bien no requirieron de capitales significativos para iniciar su ciclo productivo, sí necesitaron de los cuidados. Los plantadores debían encargarse de «limpiarlas, rozarlas y espaldearlas según los procedimientos y costumbres», comprometiéndose a la vez a entregar la totalidad de la cosecha al precio marcado por los monopolistas del fruto. ${ }^{25} \mathrm{Al}$ parecer este sistema fue mucho más efectivo que el empleado por varios hacendados quienes, a decir de Estrada, llegaron a endeudarse hasta por un monto de un millón de pesos para adquirir esclavos destinados a la limpieza de las huertas, cosechas de mazorca y demás oficios. ${ }^{26}$

Situaciones como estas en parte explican la dedicación casi exclusiva de los monopolistas cacatoeros a la exportación, más que a la misma producción, claro está con excepciones de algunos agro-exportadores como

24 Contreras, 1990, 57.

25 AHG, Escribanos públicos y judiciales, 5378, Contrato de cargas de cacao entre don Carlos Coello y don Manuel Barragán, Guayaquil, 1794.

26 Estrada, 1972, 38. 
Martín de Ycaza. ${ }^{27}$ A este respecto, Contreras refiere que en los libros de cuentas de la administración fiscal de Guayaquil en las partidas de almojarifazgo y de alcabala de cacao raras veces se registra en las guías de aduana la frase: «no se cobra alcabala por ser de su propia cosecha». ${ }^{28}$ Por tanto, infiere el citado autor que el fruto mayoritariamente exportado era previamente vendido al comerciante que lo embarcaba.

Efectivamente, quienes lo vendían eran precisamente esa red de pequeños y medianos plantadores, complementando las cargas producidas por los agro-exportadores producto de sus plantaciones generalmente superiores a 30.000 árboles. Al acaparar los diferentes espacios americanos, estos tendrían que sustentarse sobre un eficaz funcionamiento del tráfico pactando con quienes les facilitarían los procesos internos de producción y transporte.

\section{Productores y transportistas: «entrega del cacao a la orilla del río» listo para embarcar hacia otros reinos}

Los circuitos mercantiles estaban definidos por el curso de los ríos que corrían por la provincia asegurando las conexiones entre la capital y algunos partidos. Las conexiones fluviales se empalmaban con los principales caminos como el de Babahoyo a Quito, el de Yaguachi a Alausí, el de Naranjal a Cuenca y Loja. Todos ellos se enlazaban con el camino Real de Quito, también llamado camino de la Sierra o del Correo de Lima. ${ }^{29}$

Favorecidos por la red hidrográfica del Guayas para transportar el fruto desde las zonas productoras hasta los puertos de embarque tanto plantadores como comerciantes del fruto pactaban su venta puestos generalmente a la «orilla del río»:

Digo yo don Carlos Coello que debo y pagaré a don Manuel Barragán veinticinco cargas de cacao que le he vendido al precio de mi satisfacción, y me la ha pagado a precio de contado con cargo que he de poner a su disposición enjuntar y bien acondizionadas en las orillas del río de esta ciudad y su entrega la he de hacer en todo el mes de abril de este presente año, y es condición que en caso de no entregar el todo o parte desde ahora me constituyo obligado y responsable a que se haiga de comprar y

27 Soler, 2010, 132.

28 Contreras, 1990, 73.

29 Laviana, 1987, 67. 
reponer de mi cuenta al precio que se hallare dichas varas a cuyo cumplimiento me obligo con mi persona y bienes havidos y por haber en todas formas y conforme a derecho. ${ }^{30}$

Es difícil calcular estimaciones sobre los gastos de transportes desde sus corregimientos a la orilla del Guayas. Arosemena a este respecto refiere que para 1773 el precio de una carga de cacao era de 4 y 6 pesos dejando al agricultor una utilidad de más del $80 \%$; los gastos totales no eran superiores a los 6 o 7 reales (es decir un promedio de menos de un peso por carga). A partir de este dato es factible pensar su bajo costo, de ahí la preferencia de negociarlo en el lugar de embarque facilitando al comerciante exportador su ejercicio.

Como puede verse, estas entre otras participaciones colocan a los pequeños y medianos productores en el pilar fundamental de la cadena productiva y transportista del fruto al interior del Guayas. De hecho, en el puerto de Guayaquil el dinamismo comercial estuvo matizado por la concurrencia de los lugareños procedentes principalmente de Baba y Babahoyo, quienes a su cuenta y riesgo dieron salida a las cosechas.

Esta productividad se dejó sentir en el exterior, sobre todo en Nueva España, un mercado que hasta la primera mitad del siglo XVIII estuvo en manos de los caraqueños quienes suministraban el $76 \%$ del cacao para el consumo novohispano. ${ }^{31}$ No solo la disputa Caracas-Guayaquil generó tensiones entre los grupos económicos que manejaban el comercio exportador americano; existen evidencias de oposiciones entre reinos por el tráfico del fruto, una de ellas puede seguirse en el litigio seguido a Juan Camilo Helme, un comerciante con carta de naturaleza para ejercer su actividad en el Perú, quien había logrado por real orden de su majestad del 28 de marzo de 1783, licencia especial para desembarcar e introducir en el reino novohispano veinte mil cargas de cacao. Esta orden había sido dada con amplitud permitiendo embarcar desde El Callao o Guayaquil rumbo a Nueva España.

La mencionada aprobación fue presentada ante el visitador superintendente general del reino del Perú para su inteligencia y cumplimiento; no obstante su tramitación legal realizada en el Perú, la superintendencia general de Quito la desaprobó atendiendo la presión de un grupo de

30 AHG, Escribanos Públicos y judiciales, 5378, Contrato de cargas de cacao entre don Carlos Coello y don Manuel Barragán, Guayaquil, 1794.

31 Miño, 2009, 7. 
comerciantes guayaquileños, quienes ante una remisión de significativos volúmenes de cacao, vieron afectados sus intereses. Finalmente este caso fue resuelto al concedérsele poder a Francisco de Yraeta en Nueva España para hacerse cargo de dicho cacao. ${ }^{32}$

Evidencias de este tenor revelan los altos volúmenes de comercialización y la intensa labor de los cosecheros para armar expediciones de manera sistemática. De hecho, en Guayaquil se experimentó en 1785 un notorio incremento del fruto a tal punto de sufrir un fuerte retroceso en su precio. ${ }^{33}$ En consecuencia se produjo una devaluación que también afectó a quienes tenían transacciones tasadas en la especie del cacao. A este respecto es representativa la siguiente solicitud para ratificar los precios del cacao:

habiéndome hallado en los años pasados exersitado en el manejo de intereses ajenos y lo propio en la actualidad necesito hacer una plena justificación de los precios a que generalmente ha corrido el cacao desde principio de año próximo pasado de ochenta y siete hasta esta fecha para en virtud de ella satisfacer a los interesados ausentes y dar a conocer por este medio mi procedimiento en el caso de qualesquiera obstáculo que se me ponga o duda que pueda ocurrir. ${ }^{34}$

En Nueva España la oferta superó a la demanda; el tráfico marítimo se intensificó alcanzando un promedio de ocho viajes anuales, manteniéndose así hasta $1808 .{ }^{35}$ En solo el primer trimestre de 1790 arribaron a Acapulco cuatro buques complicando las ganancias de los monopolistas. Así lo hizo sentir Francisco de Yraeta a su corresponsal en Guayaquil, don Jacinto Bejarano:

la suerte de la negociación de cacao cada vez temo que sea más desagradable según la repetición que van haciendo las remesas, y la equidad con que se han comprado las partidas que han conducido los cuatro buques que han arribado a dicho Acapulco desde la declaración de la libertad, siendo lo peor que con dicho motivo y ver tanto envíos han creído aquí comprarlo muy barato no queriendo por esta causa hacer postura en ningunos términos y así nos hallamos en una inacción sin vender nada esperando que tome algún asiento. ${ }^{36}$

32 AGNM, Industria y Comercio, 13, 174-183, Solicitud permiso desembarque de cacao de don Francisco Ygnacio de Yraeta al señor fiscal de la Real Hacienda, México, sin fecha.

33 Laviana, 1987,185.

34 AHG, Escribanos públicos y judiciales, 5800, Carta al Procurador de Guayaquil del comerciante Pedro Josep Olave, Guayaquil, 1788.

35 Miño, 2009, 8.

36 Acervo Histórico Universidad Iberoamericana de México (UIA), Comercio Francisco de Yraeta, 2.1.15, 44, Carta de conocimientos enviada por Francisco de Yraeta al señor don Jacinto Bejarano en Guayaquil, México, 1790. 
La alta productividad de las cosechas desbordó las remesas. De hecho la participación masiva del grupo heterogéneo de cosecheros era latente. Estudios puntuales han demostrado que de los 95 hacendados y cosecheros registrados por los tenientes gobernadores de las provincias, el $83 \%$ estaban dentro del rango de medianos a pequeños cosecheros, con siembras entre 400 y 10.000 árboles de cacao. ${ }^{37}$

Es evidente que el tráfico cacaotero estuvo organizado por agentes principales encargados de su expansión y comercialización, y sostenidos por el sector productivo de los pequeños y medianos cosecheros, prácticas que pueden seguirse en el contrato anexo sobre expediciones de cacao y en la representación gráfica de los actores en la actividad comercial del cacao. ${ }^{38}$

\section{GRÁFICO 1}

\section{LOS ACTORES EN LA ACTIVIDAD COMERCIAL DEL CACAO}

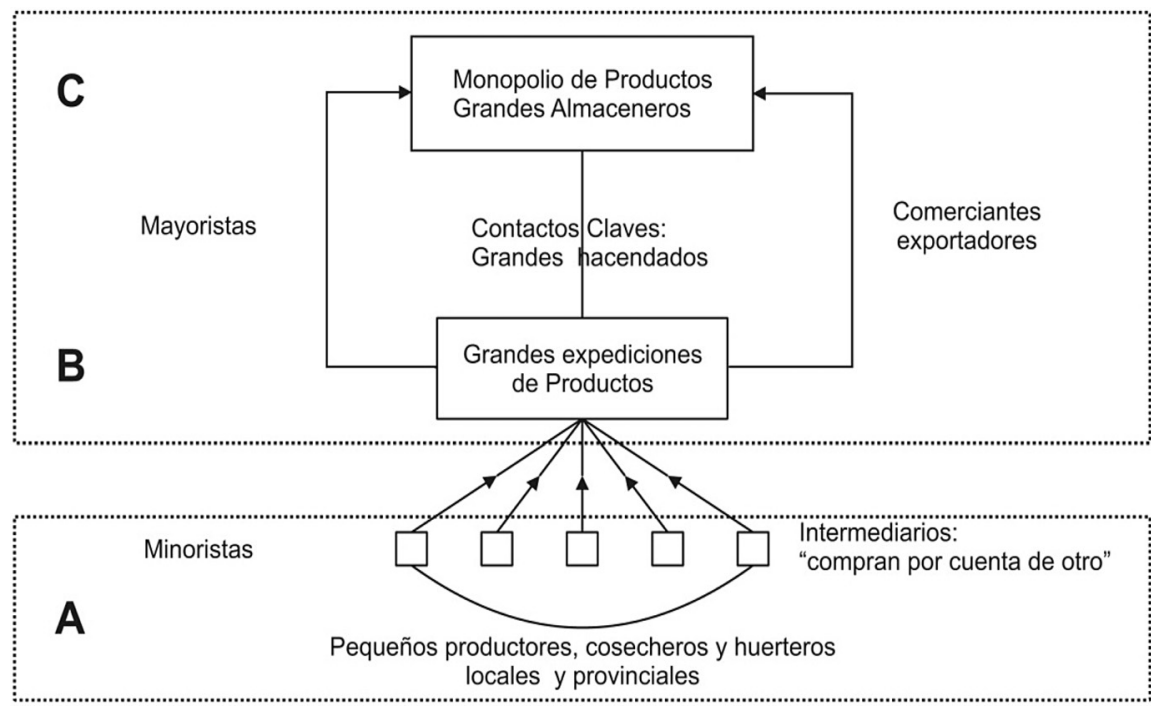

A. Almacenamiento primario entre pequeños productores a fin de constituir lotes de productos suficientes para comercializar.

B/C. Almacenamientos regulados, sujetos a factores estacionales y a los monopolios del producto.

Fuente: Elaboración propia.

37 Laviana, 1987, 177-178.

38 Anexo 1; Gráfico 1. 


\section{Entre oportunidades y vicisitudes}

Ante la abundancia del fruto y su posicionamiento en el exterior, ¿por qué no aprovechar la situación de convertirse en proveedor? Tal vez esa debió ser una pregunta de aquellos plantadores individuales que percibieron la vitalidad de un comercio reclamando constantes expediciones. Quizás ese interés masivo por el negocio del cacao les llevó a emprender contratos arriesgados buscando oportunidades para obtener beneficios, pues bien es sabido que en cuestiones de negocios unos ganan, otros pierden; lo que para algunos representó pérdidas y vicisitudes para otros ganancias y oportunidades. Aún así, generalmente es el negociante experimentado el que lleva la mejor parte, aunque esta no es una regla absoluta. Veamos algunas de las situaciones que se dieron al interior de los negocios.

\section{Usuras y excesos}

Fue costumbre generalizada recibir dinero de manera anticipada obligándose los cosecheros huerteros a la entrega de lotes de cacao sobre fechas específicas de cumplimiento. Una representación a esta práctica puede revisarse en el siguiente contrato pactado entre un cosechero de la zona y un exportador cacaotero:

Decimos don Miguel y don Gregorio Rico que por este nos obligamos a pagar al señor don Juan Antonio Rocafuerte, a saber la cantidad de treinta cargas de cacao puestas en la orilla de este rio de esta ciudad cuyo ymporte tenemos recivido en dinero, cuyas treinta cargas de cacao las entregaremos para el mes de septiembre y octubre del próccimo año venidero de setenta y nueve y a su cumplimiento, obligamos persona y bienes con toda forma de derecho y para con la presente firmamos en Guayaquil y diciembre 24 de $1778 .{ }^{39}$

De acuerdo con esta obligación, los cosecheros se aventuraban en el negocio esperando bonanza y buenos precios, no dudando comprometer sus bienes. En la práctica los pequeños cosecheros difícilmente obtuvieron jugosas ganancias y buenos precios debido a su dependencia con los mayoristas altamente controladores y manipuladores de ese mercado, quienes dependiendo de los intereses en juego aparentaban escasez o abundancia.

39 AHG, Escribanos públicos y judiciales, 4384, Contrato por cargas de cacao entre don Antonio Rocafuerte, don Miguel Rico y don Gregorio Rico, Guayaquil, 1778; AHG, Escribanos públicos y judiciales, 4384, Autos executivos don Antonio Rocafuerte contra don Miguel Eugenio Rico por 431 cargas de cacao, Guayaquil, 1781. 
El exportador, al arriesgar grandes inversiones de cacao, procuraba garantías de todo tipo; reconocido el riesgo y la manera de operar, los minoristas les delegaban sus frutos para su manejo bajo poderes amplios y suficientes. Aquel que quisiera emprender plantaciones de mayor envergadura y requiriera de efectivo debía pactar créditos a altas tasas de interés. En ocasiones, cuando los cosecheros solicitaban dinero extra para insumos debían pagar intereses generalmente usureros. Normalmente, para finales del siglo XVIII en Guayaquil los intereses a tierra corrían entre un 5 y $6 \%$ como máximo, aun así, existen varias evidencias de pagos de réditos hasta de un $8 \%$, incluso cuando el prestamista también había entrado en el negocio o en composición mutua. ${ }^{40}$

Así lo declaraba un incauto negociante de cacao quien pactó tratos con un reconocido exportador del fruto: «el mayor interés que hoy se tira en el comercio por razón del lucro no excede de un cinco o seis por ciento y vuestra alteza ha declarado que cuando se da en mutuo asegurándose el principal con fundos, como sucede al presente, no se exija más que el quatro». ${ }^{41}$

Este irregular procedimiento iba más allá, así lo declaró Diego Bayas ante tribunales: «Algunas ocasiones de que estrechado de la necesidad de cultivar las huertas para cumplir el crédito le pedía dinero, no se lo quería dar sino con la precisa condición de entregárselo a riesgo de mar con el interés de veinte por ciento». ${ }^{42}$

No resulta extraño encontrar demandas por cantidad de pesos a individuos que aprovechando fama y caudales lucraron a costa de los pequeños huerteros. De hecho, las quejas fueron recurrentes sin lograr un dictamen a favor. Las múltiples denuncias a Manuel Barragán (uno de los más importantes compradores mayoristas de las principales zonas productoras de cacao: Baba, Palenque, Babahoyo y Machala), pueden seguirse en el tribunal de Quito por abusos e impunidad sobre los excesos:

para prueba de la legalidad de este suxeto de usurarias negociaciones y de mala versación de modo que este es el ordinario trato y proceder con que dicho Barragán trata con cuanto incautos negocian con él, labrándose su caudal a fuerza de usuras

40 AHG, Escribanos públicos y judiciales, 4829, Autos executivos seguidos por préstamos a interés entre Josep Fermín Rivera y varios comerciantes contra Manuel Barragán, Guayaquil, 1784.

41 AHG, Escribanos públicos y judiciales, 5458, Resumen del expedientes por autos executivos seguidos por don Diego Bayas contra don Manuel Barragán, Guayaquil, 1784-1793

42 Archivo Nacional del Ecuador, Quito (ANE), Pesos, 143, 5, Autos seguidos por don Miguel de Olmedo contra don Manuel Barragán, Quito, 1783. 
y de ilícitos comercios con detrimento de sus contrayentes, pero como al mismo tiempo es un hombre acaudalado y enredado en crecidas negociaciones con los vecinos de Guayaquil se hace allá quasi imposible cortar estos excesos y someterlos a justicia. ${ }^{43}$

Los reiterados esfuerzos del denunciante (que en este caso era un reconocido comerciante de Quito) por enfatizar en el deshonor del comerciante por las prácticas usureras se entienden mejor si se tiene en cuenta que en la época colonial eran particularmente importantes el honor y la credibilidad. Por lo tanto, dictaminar en su contra no era conveniente para los jueces de comercio, involucrados dentro del mismo grupo monopólico.

Otro caso representativo es la querella entre Josep Juan de Echavarría y Pedro de Arteta, este último, un reconocido comerciante de Guayaquil y Lima, hermano de Damián de Arteta, apoderado del vecindario de Guayaquil para exportar cacao a Nueva España.

Veamos los entresijos íntimos de esta contienda. En una primera demanda el juez de comercio Antonio Rocafuerte dictaminó sentencia contra Pedro de Arteta, quien debía pagar mil pesos al dicho Echavarría. No conforme con la sentencia buscó dilatar el proceso solicitando al juez los autos quedándose con el expediente; ante tal actuación replicó el procurador Martínez:

en estado de alegar para cuyo efecto se entregaron los autos a don Pedro quien entreteniendo el tiempo con ellos en su poder sin deducir cosa alguna, marchó a Lima sin dejar ningún apoderado y quedando en consecuencia el juicio suspenso y mi parte sin poder practicar diligencia alguna. En Lima consiguió la Judicatura del comercio volvió a esta ciudad, dijo a mi parte que se resolvería el asumpto luego que se recibiese su compañero, esto no se ha verificado, pero con estar entretenidas ha conseguido entorpecer el curso de la causa, y en todo caso los autos guardados, sin ser capas de expediente y corte alguno por más que se le ha suplicado. ${ }^{44}$

Otro caso que representa los excesos de poder y de autoridad es el del gobernador Pizarro. Si bien este individuo promovió el proyecto de plantar cacao para el comercio exterior, un emprendimiento que según Laviana involucró a 97 agricultores con plantaciones entre 350 y 92.310 árboles, ${ }^{45}$

43 Idem.

44 AHG, Escribanos públicos y judiciales, 4719, Autos executivos presentados por Antonio Martínez Procurador a nombre del Capitán de Milicias don Josep Juan de Echavarría contra don Pedro de Arteta por incumplimiento de instrumento público, Guayaquil, 1784.

45 Laviana, 1987, 177. 
tal esfuerzo terminó beneficiando sus propios intereses y los de los grupos monopolistas; de hecho, los plantadores y cosecheros sufrieron los abusos de Pizarro, quien fue acusado de agiotista, de vender sus votos a los cargos de alcalde y de confabularse con los terratenientes para obligar a los cacaoteros a aceptar la mitad del precio por sus cosechas. ${ }^{46}$

En las mismas circunstancias, plantadores y cosecheros instauraron demandas contra el grupo del gran cacao conformado por Manuel Barragán, Jacinto Bejarano, Bernardo Roca y Martín de Ycaza, acusados por monopolizar la cuota anual de fanegas de cacao hacia Nueva España, y bajar los precios hasta el punto de forzar a varios cosecheros abandonar su negocio. ${ }^{47}$

Estas prácticas demuestran cómo el cosechero huertero productor dependiente de materia prima y deudor de caudales, estuvo atrapado en contratas, subcontratas y usuras. Con todo, las arbitrariedades e injusticias no dejaron inmune incluso a las mismas autoridades; no sin razón, el capitán Andrés Herrera Campuzano se pronunció en los siguientes términos: «los infelices cosecheros, hijos de la patria, y llenos de infelicidad, gimen bajo el yugo de estos tiranos que engrosan sus caudales». ${ }^{48}$

\section{Préstamos e hipotecas}

Dentro de las prácticas del ejercicio mercantil los juicios y contiendas son una constante universal, no siendo igual uno de los avatares vividos en la cotidianidad del Guayaquil colonial: plantar cacao para liberar préstamos o hipotecas.

Antonio Yllescas representa al tipo de cosechero-huertero que por incumplimiento de contrato de un tercero, y en calidad de fiador, tuvo que asumir una deuda ajena. Dicha obligatoriedad quedó expresada en el siguiente fragmento de una demanda: «trescientas setenta y cinco cargas de

46 Archivo General de Indias (AGI), Quito, 271, Quejas de don Andrés Herrera Campuzano, regidor de Guayaquil y capitán de milicias, contra el gobernador y teniente de gobernador de Guayaquil, Guayaquil, 1782-1788; Archivo General de Simancas (AGS), Secretaría de Guerra, 7054, Quejas contra el gobernador de Guayaquil, Guayaquil, 1790.

47 La Real Orden de 1778 impuso límite de diez mil fanegas para exportar cacao Guayaquil a Nueva España. En 1789 se libera esta cuota. En la práctica, estos límites no se cumplieron por constantes licencias especiales concedidas por la corona y por el contrabando. Soler, 2010.

48 AGI, Quito, 371, Queja de don Andrés Herrera Campuzano, regidor de Guayaquil y capitán de milicias, contra el gobernador y teniente de gobernador de Guayaquil, Guayaquil ,1790. 
cacao cantidad que le debe dicho Yllescas por separada escritura y con hipoteca expresa de una huerta de cacao nombrada San Josep y tierras que se expresan en dicha escritura según consta». ${ }^{49}$

Al declararse insolvente su acreedor, don Bernardo Roca, no dudó en replicar lo siguiente: «me vi precisado dicho mi parte en este presente año de habilitar con dinero al dicho don Joaquín para que pudiese cosechar las huertas embargadas del principal deudor Yllescas y facilitarse de esto modo el pago».50

La estrategia utilizada por el acreedor de inyectar capital para habilitar los plantíos refleja la necesidad apremiante del fruto más que la misma hipoteca. De hecho, el comerciante exportador realizaba negociaciones previas con las redes internacionales y estaba en juego su debido cumplimiento. Atender la exportación por El Callao hacia Cádiz y/o por su mismo puerto rumbo hacia otros destinos americanos implicaba armar las expediciones a toda costa; la ampliación del comercio hacia otros puertos que no eran El Callao ni Acapulco representó un 8 \% entre 1791 y 1793. En 1796 se abrió al comercio libre el puerto californiano de San Blas y en los primeros años del siglo siguiente Panamá, Sonsonate y Realejo, absorbiendo el $27 \%$ de las exportaciones de Guayaquil. ${ }^{51}$

\section{Pactos desventajosos}

Quienes querían incursionar en el tráfico de la almendra prácticamente tendrían que apostar lo que tenían: sus tierras y sus cosechas. El riesgo mayor fue para quienes no contaban con capitales líquidos, ni con una sólida solvencia económica debiendo financiarse con figuras crediticias singulares.

La representación más fehaciente de esta situación puede seguirse en la demanda de Diego Bayas, quien había recibido del exportador Manuel Barragán cuatro mil pesos en dinero según consta en la escritura fechada el «veintisiete de enero de ochenta y cuatro» y dos mil pesos que anteriormente debía, obligándose a satisfacer en especie de cacao con las siguien-

49 AHG, Escribanos públicos y judiciales, 4845, Resumen de expediente por autos executivos seguidos a don Antonio Yllescas por don Bernardo Roca por cargas de cacao, Guayaquil, 1786.

50 Idem.

51 Contreras, $1990,81$. 
tes prebendas: por carga de cacao debía rebajar a favor del acreedor seis reales al más alto precio que se hubiera vendido, además del $8 \%$ que debía pagar por año sobre las hipotecas de las mismas huertas compradas. ${ }^{52}$

Con un contrato en estas condiciones difícilmente se podría evitar la ruina. En efecto la deuda ascendió a 6.753 pesos 3 reales, denunciando el deudor que «en cada carga de cacao le estrechó a que le cediese el importe de la conclusión del diezmo que es un peso por carga de las que se entregan al diezmero». ${ }^{53}$ La deuda que inicialmente estaba estipulada en 6.000 pesos, para el año siguiente «el dos de julio del año de mil ochocientos ochenta y cuatro la obligación era de 13.959 pesos $1 \frac{1}{1} 2$ reales». ${ }^{54}$

Por todo lo anterior, el denunciante no dudó en señalar que:

el delito de usura sea uno de los más execrables dicho don Manuel hombre poderoso por su caudal y conexiones, mi parte destituido de estas qualidades, y sujeto a la más infeliz fortuna por haber contratado con él [...] la usura según explica la ley de Castilla es un gran pecado y prohibida por todo derecho trae muchos daños a la República, y el usurero es comparado al ladrón famoso: es digno del mayor castigo este delito y por lo mismo debe juzgar al autor de él un Tribunal tan recto y justificado como el de vuestra alteza para que no tenga lugar la cavilación, y quede impune..$^{55}$

Si bien los casos anteriores representan a los menos afortunados en sus negocios, es lógico advertir casos de cosecheros que aun comprometiendo sus haberes obtuvieron ganancias, y/o paradójicamente, casos de mayoristas con solvencia económica que no necesariamente terminaron con éxito.

\section{Embargos y remates}

Los autos seguidos contra Vicente del Castillo nos facilitan representar esas situaciones universales de despojo:

por la cantidad de ciento noventa cargas cincuenta y dos libras de cacao que había de satisfacer por los meses de agosto y septiembre del presente año y sin embargo de las

52 AHG, Escribanos públicos y judiciales, 5458, Resumen de expediente por autos executivos seguidos por don Diego Bayas contra don Manuel Barragán, Guayaquil, 1784-1793.

53 Idem.

54 Idem.

55 Idem. 
reconvenciones amistosas que se le hicieron al intento después que cumplió el plazo no ha sido posible que satisfaga. En cuya virtud a vuestra merced pido y suplico se sirva mandar librar despacho para el Teniente de Gobernador de las Reales Bodegas de Babahoyo a efecto de que haciendo reconocer a dicho don Vicente del Castillo su firma y pacto del nominado documento, luego que confiese el previsto al pago, y si no lo verifica le embargue qualesquier bienes de su pertenencia los necesarios para este pago hasta el remate y venta de ellos que puedan componer el total al precio que corre el cacao. ${ }^{56}$

Las negociaciones en las cantidades de cacao que recibieron los comerciantes exportadores dependieron de la crucial concertación y negociación con los proveedores del fruto. El no cumplimiento afectaría tratos a escalas mayores, por eso las arriesgadas operaciones tendrían que ser aseguradas con bienes en garantía, aunque no siempre fueron suficientes porque algunos se declaraban insolventes.

En general un comerciante exportador resarciría ventajosamente sus contratos con las garantías de los semovientes. Bernardo Roca, fiador de Nicolás Cornejo, solicitó los servicios de Pacheco y Avilés para realizar diligencia de embargo. Este es el fragmento de una misiva enviada a Bernardo Roca, sobre el mencionado adelantamiento:

Muy estimado compadre y querido amigo. El miércoles salí para el Palenque a practicar su diligencia, que regresé ayer esta su casa a las siete de la noche: remito los autos con las diligencias practicadas en la forma que aparecen hecho en el embargo del sitio; y ganados que es lo que más siente el interesado y yo contemplando que el ganado es la especie más apetecible me pareció mejor que no esos esclavos insolentados que necesitan cogerlos a bala. ${ }^{57}$

Si bien los esclavos brindaban otra posibilidad de recuperar sus inversiones, es entendible la elección en el mencionado remate, puesto que en Guayaquil a diferencia de otros modelos americanos de las grandes plantaciones de café, algodón y azúcar con mano de obra esclava, se emplearon a los habitantes serranos de Quito y a los sectores aledaños para el trabajo en las plantaciones.

56 AHG, Escribanos públicos y judiciales, 4279, Autos executivos seguidos por el apoderado del Coronel de Milicias Jacinto Bejarano contra don Vicente Severo del Castillo por cantidad de cargas de cacao, Guayaquil, 1779.

57 AHG, Escribanos públicos y judiciales, 5378, Carta escrita a Bernardo Roca por Pacheco y Avilés sobre diligencias de cobro, Baba, 1792. 


\section{Consideraciones finales}

Los lugares yuxtapuestos de los diferentes actores involucrados en el comercio del cacao representados en los documentos notariales han permitido destacar prácticas, acciones u omisiones, estrategias y entresijos de quienes tuvieron que solventar dificultades y/o aprovechar las posibilidades del comercio de un fruto altamente especulativo.

Este texto demostró la significativa participación de los minoristas conformados por pequeños y medianos productores locales y provinciales, destacando su rol fundamental en la creciente y sostenida producción y comercialización del fruto. Los grupos de monopolistas guayaquileños no hubieran logrado cubrir y cumplir contratas previamente negociadas con las redes internacionales sin las constantes cuotas de sus principales proveedores. Para comprender esa alta participación basta con revisar los datos del grano exportado a los distintos destinos americanos, aún sin contar con el cacao directamente exportado por El Callao vía Cádiz y con el tráfico del comercio subrepticio conocido por todos.

Sobre la base de datos oficiales se encontró que entre los años de 1787 y 1796 se registró en puertos y en la contabilidad fiscal de Guayaquil la salida de 652 mil cargas del mencionado fruto con destino a diferentes puertos americanos, manteniendo promedios anuales de cargas superiores a 50 mil, excepto en el año $1788 .^{58} \mathrm{Si}$ bien este es un tema que requiere mayor detenimiento y análisis y que escapa a las pretensiones de este texto, su referencia permite ver las exportaciones sistemáticas de la almendra, siendo los cosecheros plantadores los productores primarios, quienes proveían esta especie valorada en el extranjero. Paradójicamente, y muy a pesar de los lugareños, mientras en el interior el precio de cacao era devaluado por quienes controlaban los precios y los almacenamientos, en el extranjero sucedía lo contrario constituyéndose en un negocio altamente redituable para los grandes mayoristas. En consecuencia, al imponerse los monopolios estos sectores quedaron bajo su sombra, y si bien algunos cosecheros-huerteros sobrevivieron acomodándose al sistema impuesto, otros sucumbieron. 
GRÁFICO 2

EXPORTACIÓN ANUAL DE CACAO GUAYAQUIL (1787-1797)

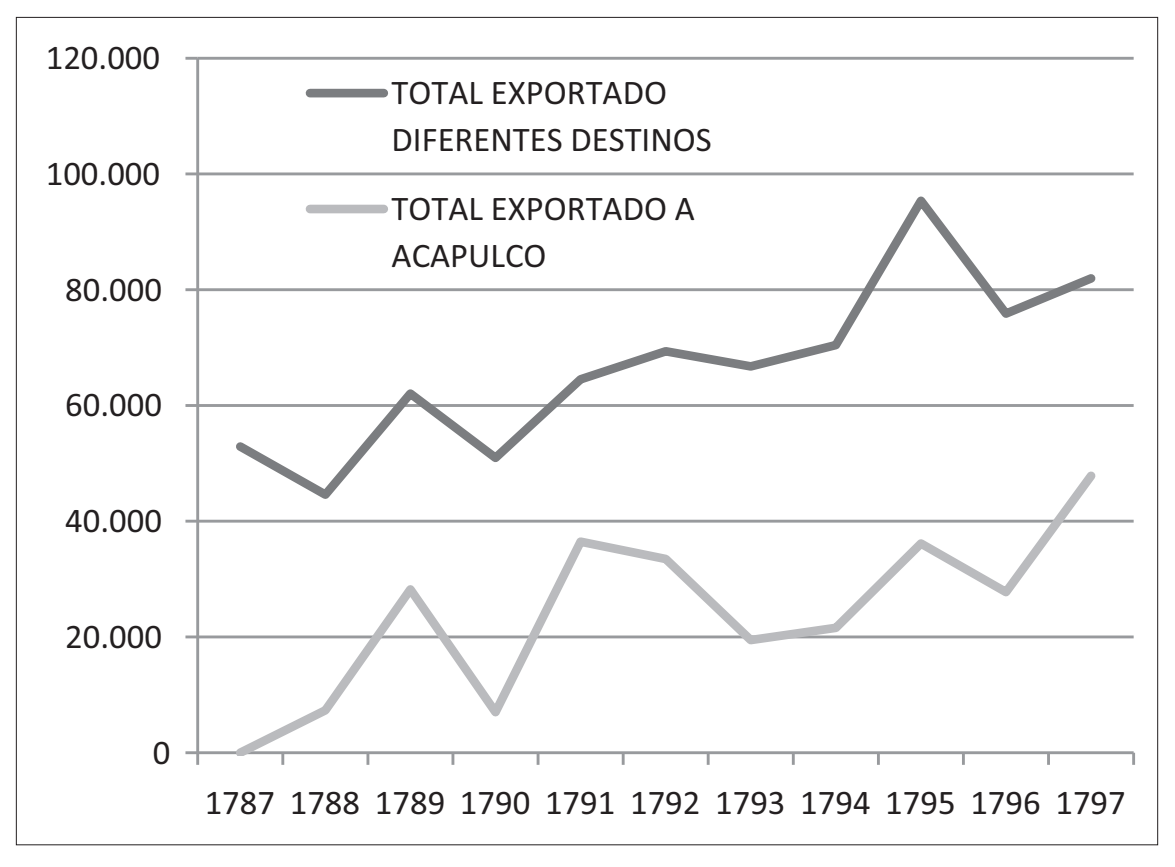

Fuente: Elaboración propia a partir de datos de Laviana, 1987, 186. 
TABLA 1

RESUMEN EXPORTACIÓN ANUAL DE CACAO POR GUAYAQUIL A ACAPULCO (1787-1797)

\begin{tabular}{|c|c|c|c|rl|}
\hline Año & Total $(1)$ & Acapulco $(1 a)$ & Total $(2)$ & \multicolumn{2}{|c|}{ Acapulco $(2 a)$} \\
\hline 1787 & 52.888 & \multicolumn{2}{|c|}{ Sin datos } & $(59.409)$ & $9.976 \quad(17 \%)$ \\
\hline 1788 & 44.579 & $7.319(16 \%)$ & 36.310 & $7.319 \quad(20 \%)$ \\
\hline 1789 & 62.046 & $28.199(45 \%)$ & 60.223 & $26.939 \quad(45 \%)$ \\
\hline 1790 & 50.954 & $7.000(14 \%)$ & $(58.016)$ & $20.755 \quad(36 \%)$ \\
\hline 1791 & 64.519 & $36.466(56 \%)$ & 62.840 & $34.676 \quad(55 \%)$ \\
\hline 1792 & 69.356 & $33.478(48 \%)$ & $(60.060)$ & $32.483 \quad(55 \%)$ \\
\hline 1793 & 66.751 & $19.470(29 \%)$ & 65.394 & $18.270 \quad(28 \%)$ \\
\hline 1794 & 70.435 & $21.576(31 \%)$ & 79.750 & $29.622 \quad(37 \%)$ \\
\hline 1795 & 95.365 & $36.138(38 \%)$ & 94.820 & $35.139 \quad(37 \%)$ \\
\hline 1796 & 75.877 & $27.752(37 \%)$ & 75.536 & $16.529 \quad(21 \%)$ \\
\hline 1797 & 81.957 & $47.842(58 \%)$ & 82.350 & $47.842 \quad(58 \%)$ \\
\hline TOTAL & 734.727 & $265.240(36 \%)$ & 734.708 & $279.550 \quad(38 \%)$ \\
\hline
\end{tabular}

(1) Total cargas de cacao exportado por el puerto de Guayaquil a los diferentes destinos americanos. Datos tomados sobre la contabilidad fiscal de Guayaquil por Laviana Cuetos, María Luisa: Guayaquil en el siglo XVIII Recursos naturales y desarrollo económico, Sevilla, Escuela de Estudios Hispano-Americanos, 1987, 186.

(1a) Total de cargas de cacao exportado por el puerto de Guayaquil a Acapulco. Idem.

(2) Total cargas de cacao exportado por el puerto de Guayaquil a los diferentes destinos americanos (Payta, Callao, Guanchaco, Valparaíso, Iquique, Arica, Pisco, Chocó, Panamá, Sonsonate, Realejo y Acapulco). Datos tomados sobre movimiento portuario de Guayaquil por Arosemena Arosemena, Guillermo: El fruto de los dioses. El cacao en el Ecuador, desde la colonia hasta el ocaso de su industria, 1600-1983, Guayaquil, I, Graba Editorial, 1991, 130-166. Los valores entre paréntesis indican modificación a los datos presentados por Arosemena. Estos corresponden a ajustes nuestros, resultado de la comprobación de sumas parciales.

(2a) Total de cargas de cacao exportado por el puerto de Guayaquil a Acapulco. Datos tomados sobre movimiento portuario de Guayaquil por Arosemena. Idem.

Fuente: Elaboración propia a partir de datos de Laviana y Arosemena. 


\section{Bibliografía}

Arosemena Arosemena, Guillermo: El fruto de los dioses. El cacao en el Ecuador, desde la colonia hasta el ocaso de su industria, 1600-1983, Guayaquil, I, Graba Editorial, 1991.

Benavente, Fray Toribio de (Motolinía): Historia de los indios de la Nueva España, ed. de Edmundo O'Gorman, México, Editorial Porrúa, 1984.

Chiriboga Vega, Manuel: Jornaleros y Gran propietarios en 135 años de exportación cacaotera (1790-1925), Quito, CIESE, 1980.

Clayton, Lawrence: Los Astilleros de Guayaquil colonial, Guayaquil, Archivo Histórico del Guayas, 1978.

Contreras Carranza, Carlos: El sector exportador de una economía colonial. La costa del Ecuador entre 1760-1820, Quito, FLACSO/Abya-Yala, 1990.

Dueñas de Anhalzer, Carmen: Marqueses, cacaoteros y vecinos de Portoviejo, Cultura Política en la Presidencia de Quito, Quito, Universidad San Francisco de Quito/Abya-Yala 1997.

Erneholm, Ivar: Cacao Production of South America. Historical Development and Present Geographical Distribution, Göteborg, Holmquists Boktryckeri, 1948.

Estrada Ycaza, Julio: El puerto de Guayaquil: Crónica portuaria, Guayaquil, Archivo Histórico del Guayas, 1972-73, 2 vols.

Hamerly, Michel T.: Historia Social y Económica de la antigua provincia de Guayaquil 1763-1842, Guayaquil, Archivo Histórico del Guayas, 1973.

Hamerly, Michel T.: El comercio del cacao de Guayaquil durante el periodo colonial, un estudio cuantitativo, Historia Marítima del Ecuador, 4, Quito, Comandancia General de Marina, 1976.

Hernández Jaimes, Jesús: «El fruto prohibido. El cacao de Guayaquil y el mercado novohispano, siglos XVI-XVIII», Estudios de Historia Novohispana, 39, México, julio-diciembre 2008, 43-79.

Laviana Cuetos, María Luisa: «Organización y funcionamiento de las Cajas Reales de Guayaquil en la segunda mitad del siglo XVIII», Anuario de Estudios Americanos, XXXVII, Sevilla, 1980, 313-346.

Laviana Cuetos, María Luisa: La Descripción de Guayaquil por Francisco Requena, 1774, Sevilla, Escuela de Estudios Hispano-Americanos, 1984.

Laviana Cuetos, María Luisa: Guayaquil en el siglo XVIII. Recursos naturales y desarrollo económico, Sevilla, Escuela de Estudios Hispano-Americanos, 1987.

Mazzeo de Vivó, Ana Cristina: Los comerciantes limeños a fines del siglo XVIII Capacidad y cohesión de una élite, 1750-1825, Lima, Pontificia Universidad Católica del Perú, 1999.

Miño Grijalva, Manuel: «El "cacao guayaquil” en Nueva España, siglo XVIII», Estudios Mexicanos, 25-1, California, University of California, 2009, 1-17. 
León Borja, Dora y Szasdi Nagy, Adam: «El comercio del cacao de Guayaquil», Revista de Historia de América, 57-58, México, 1964, 1-50.

León Borja, Dora: «Los indios balseros como factor en el desarrollo del puerto de Guayaquil», en Estudios sobre política indigenista española en América, II, Valladolid, 1976, 281-311.

Soler Lizarazo, Luisa Consuelo: "Tráfico mercantil entre España y Guayaquil. Francisco de Yraeta y sus corresponsales, 1770-1797”, Tesis doctoral, Universidad Iberoamericana de México, 2010.

Valle Pavón, Guillermina del: «Comercialización del cacao de Guayaquil por los mercaderes del Consulado de México en la segunda mitad del siglo XVIII», Estudios Mexicanos, 26-2, California, University of California, 2010, 181-206. 



\section{Anexo documental}

\section{Contrato de expedición de cacao hacia Acapulco. AHG, Escribanos Públicos, 5833}

En la ciudad de Santiago de Guayaquil en dieciocho días del mes de nobiembre de mil setecientos setenta y nuebe años: ante mí el escribano público, y testigos parecieron presentes de la una parte, el Coronel del Batallón de Milicias arregladas de Infantería don Jacinto Bejarano, el capitán don Pedro de Arteta y el capitán don Miguel de Olmedo y don Silvestre Gorostiza Villamar y de la otra, el doctor don Damián de Arteta vecinos de esta ciudad a quienes doi fee conozco los primeros como los directores de la expedición [borroso] de Acapulco [deteriorado] don Damián de Arteta ha estar dispuesto para embarcarse a la hora, que el maestre del navío llamado la Balvaneda (donde se conduce la mayor parte de estos cacaos) le avise, que va aserse a la vela respecto a que en esta embarcación ha de hacer su viaje, que por razón de comisión ha de sacar el dicho don Damián de la total importancia de los cacaos en su venta por la razón de premio un quatro por ciento que llevaría para assí, y sin que a la expedición pueda gravarla en más cantidades que verifíque o no se verifique remesa de cacao en esos años [borroso] [...deteriorado] dinero efectivo de los accionistas interesados en la remición y si faltare alguno deverá dejar persona con poder vastante y aceptado para que se satisfaga cuando sea recombvenido= Que su Majestad (Dios le guarde) les conseda la gracia según la pretensión que tienen hecha de aumentar la cuota señalada de cacao que en el día ha limitado, y dispongan su remición a de ser obligado el dicho don Damián a recibirla estando en México en todas las ocasiones que se le manden llevando solo por la citada comisión seis mill pesos y en este caso la presente queda reputada por los mismos seis mil pesos= que a la buelta de la Balvaneda en este presente viaje es del [borroso] [...deteriorada media hoja] [...borrosa una hoja completa] dicho don Damián [borroso] siendo testigos presentes don Jossep Guillermo Gutierrez, Don Jossep Rodríguez y don Jossep Ignacio de Cassanova de que doy fee fee Jacinto Bejarano, Pedro de Arteta, Miguel de Olmedo, Silvestre Gorostiza Villamar, Damián de Arteta ante mi Alexo Giraldo Pereira [borroso...] [firmas]. 